\title{
Seasonality in Atypical Depression
}

\author{
Atul C. Pande, Roger F. Haskett, and John F. Greden
}

\section{Introduction}

One definition of atypical depression has emphasized the reversed vegetative symptoms (hypersomnia and hyperphagia) (Aarons et al 1985) in the context of a nonendogenous (or mood reactive) depressive state (Ravaris et al 1980). This clinical picture overlaps with Seasonal Affective Disorder (SAD) (Rosenthal et al 1984), which is a syndrome of recurrent depressions associated with fatigue, hypersomnia, hyperphagia, carbohydrate craving, weight gain, and interpersonal difficulties. Whether the two conditions are variants of a common underlying disorder is unclear although, based on the lack of response to phototherapy in eight atypical depressive patients, Stewart et al (1990) have suggested that atypical depression and SAD are separate disorders. A comparison of seasonality in several clinical populations and normals (Hardin et al 1991) showed that patients with SAD, subsyndromal SAD, and eating disorders had significantly higher seasonality scores than bipolar disorder, major depression (including a subset of atypical depressives), and normals.

Clinically we noted that although atypical depressives may not meet specific criteria for SAD (especially the seasonal onset and remission), many of them exhibit a seasonal pattern of severity comparable to the SAD patients. In

\footnotetext{
From the Depression Program, Department of Psychiatry, University of Michigan Medical Center. Ann Arbor, Michigan.

Address reprint requests to Atul C. Pande, MD, 9D9702 UH, Box 0118, University of Michigan Medical Center, 1500 East Medical Center Drive, Ann Arbor, MI 48109-0118.

Received September 30, 1991; December 16, 1991.

Presented as a poster at the Society of Biological Psychiatry Annual Meeting, New Orleans, LA, May 1991.
}

the present study we examined whether patients with mood-reactive atypical depression (Quitkin et al 1984) demonstrate a seasonal pattern in their mood-related symptoms, and if atypical depressives with and without a seasonal pattcrn differ on demographic or clinical features.

\section{Method}

The sample consisted of 30 (26 women, 4 men) patients with Major Depressive Disorder ( $n=$ $28)$ or Dysthymia $(n=2)$ along with atypical depressive synuptoms who were sought for a drug treatment study. Subjects included (1) outpatients from the University of Michigan Hospital Depression Program clinic, and (2) responders to newspaper advertisements run continuously between January and December 1990. Patients from the two sources did not differ on demographics or depression severity measures. All patients were drug-free for 2 weeks and met the Columbia criteria for atypical depression (Quitkin et al 1984). Patients with nondepressive DSM-III-R diagnoses (e.g., substance abuse or dependence) or definite bipolar disorder were excluded. Prior to any treatment, patients completed the Symptom CheckList (SCL. 90) (Derogatis et al 1977), and the Seasonal Pattern Assessment Questionnaire (SPAQ) (Rosenthal et al 1984). The SPAQ inquires about seasonal changes in sleep length social activity, mood, appetite, weight, and energy level, which are rated from 0 (no change) to 4 (extreme change). The item scores add up to a general seasonality score ranging from 0 to 24 . A score of 10 or more classifies a definite seasonal pattern, whereas scores of $8-9$ indicate a subsyn- 
dromal SAD pattern (Kasper et al 1989). Scores of 7 or less are common in nonSAD populations. Severity of depressive symptoms was rated on the 17-item Hamition Rating Scale for Depression (HRSD) (Hamilton 1967) by raters blind to the SPAQ data. Atypical depressive symptoms were scored on the Columbia scale.

\section{Results}

The general seasonality score (GSS) in our sample ranged from between 2 to 18 (mean \pm $\mathrm{SD}=11.2 \pm 5.1,95 \%$ confidence limits $=$ 9.3-13.2). Nineteen subjects (63\%) had a GSS $\geq 10$ (mean $\pm S D=13.8 \pm 2.1$ ), two patients (7\%) had a GSS of 8-9 (mean \pm SD $=7.5$ $\pm 0.7)$, whereas $9(30 \%)$ had a score of $\leqslant 7$ (mean $\pm \mathrm{SD}=4.5 \pm 1.7$ ). Comparisons were made between two groups divided by the cutoff of 10 (Table 1). Those with a seasonal pattern had marked seasonal variations in their mood, sleep, appetite and energy levels, with the fall and winter being the worst times. The groups did not differ for demographic data, the severity of depression or any of the SCL-90 dimensional scores. Interestingly, the seasonal atypicals had significantly lower body weight than the nonseasonals. Response to drug treatment with fluoxetine or phenelzine was not related to seasonality scores (Pande et al 1991).

\section{Discussion}

This study found a high seasonality scers in over half the patients with mood-reactive atypical depression. The seasonal atypicals did not differ on demographic or symptom measures from the nonseasonal patients. Patients sampled at different times of year reported similar levels of seasonality. The most pronounced annual variations reported were in mood, sleep, appetite, and energy, much in the same manner as for SAD with a winter pattern. However, all of our patients had a chronic course i f their depressive illness, which is unlike SAD.

Our findings contradict the suggestion by Stewart et al (1990) that SAD and atypical depression are separate entities. Their conclusion was based on the nonresponse to light therapy in eight atypical depressives withoul a seasonal pattern. Our patients were treated with antidepressant medication, hence we cannot say if phototherapy may have been effective. The deliberate exclusion by Stewart et al of patients with a seasonal pattern may have excluded atypical depressive patients who may be responsive

Table 1. Comparison of Atypical Depressions with High and Low GSS

\begin{tabular}{lcc}
\multicolumn{1}{c}{ Parameter } & $\begin{array}{c}\text { SPAQ } \leqslant 9 \\
(n=11)\end{array}$ & $\begin{array}{c}\text { SPAQ } \geqslant 10 \\
(n=19)\end{array}$ \\
\hline Age & $36.3 \pm 8.8$ & $36.2 \pm 8.9$ \\
Height & $66.1 \pm 4.7$ & $63.7 \pm 2.4$ \\
Weight & $188.9 \pm 43.9$ & $151.4 \pm 33.8^{b}$ \\
General Seasonality & $5.1 \pm 2.0$ & $14.5 \pm 2.5^{c}$ \\
Score & $(3.7-6.6)^{a}$ & $(13 . j-15.7)^{a}$ \\
Total HRSD (17-item) & $13.4 \pm 1.8$ & $13.8 \pm 2.1$ \\
Atypical scale items & & $3.2 \pm 0.7$ \\
$\quad$ Mood reactivity & $3.3 \pm 0.7$ & $2.9 \pm 1.6$ \\
$\quad$ Hypersomnia & $2.7 \pm 1.7$ & $3.9 \pm 1.2$ \\
$\quad$ Hyperphagia & $3.5 \pm 1.7$ & $3.4 \pm 1.2$ \\
Weight gain & $3.6 \pm 2.0$ & $9119(47 \%)$ \\
Rejection sensitivity & $3111(27 \%)$ & $1.7 \pm 0.7$ \\
SCL-OC & $1.8 \pm 0.8$ & \\
\hline
\end{tabular}

All values show mean \pm SD except rejection sensitivity.

${ }^{\circ}$ Confinence limit interval of $95 \%$.

${ }^{b} p<0.02$

$' p<0.0001$ (two tailed $t$-tests), all others NS. 
to bright-light treatment even though they do not meet specific SAD criteria. Inclusion of atypical depressives with and without a seasonal pattern in phototherapy protocols would be necessary to establish the differential efficacy of phototherapy in this illness. Furthermore, if treatment response is to serve as a validating criterion, a more informative design may be a randomized comparison of monoamine oxidase inhibitoss, fluoxetine, phototherapy, and perhaps cognitive therapy in a consecutive series of atypical depressives stratified by the presence or absence of a self-reported seasonal pattern.

The finding of lower-body weight in seasonal atypicals remains unexplained. Because many of the patients struck us clinically as being greatly preoccupied with appe ite and weight concerns, we wondered about ubsessive over-reporting. However, their score on the Obsessive-Compulsive dimension of the SCL-90 was similiar to that of the nonseasonals. Other explanations may exist for this finding, for example, that seasonal atypicals may have greater weight fluctuations annually than nonseasonal atypicals. The latter group by virtue of chronic atypical depressive symptoms of unchanging severity may approach morbid obesity. Whether distinct metabolic differences exist between the seasonal and nonseasonal atypicals must remain an open question.

Other validating strategies to delineate the relationship between atypical depressica and SAD include family history study and longitudinal follow-up study, both of which we an: currently pursuing.

\section{References}

Aarons SF, Frances AJ, Mann JJ (1985): Atypical depression: A review of diagnosis and treatment. Hosp Community Psychiatry 36:275-282.

Derogatis LR, Cleary PA (1977): Factorial invariance across gender for the primary symptom dimensions of the SCL-90. BrJ Soc Clin Psychol 16:347-356.

Hamilton M (1967): Development of a scale for primary depressive illness. Br J Soc Clin Psychol 6:278-296.

Hardin TA, Wehr TA, Brewerton T, et al (1991): Evaluation of seasonality in six clinical and two normal populations. J Psychiatr Res 25:75-88.

Kasper S, Wehr TA, Bartko JJ, Gaist PA, Rosenthal NE (1989): Epidemiological findings of seasonal changes in mood and behavior. A telephone survey of Montgomery County, Maryland. Arch Gen Psychiatry 46:823-833.

Pande AC, Haskett RF, Greden JF (1991): Doubleblind comparison of fluoxetine and phenelzine in atypical depression. Biol Psychintry 29:117A.

Quitkin FM, Harrison W, Liebowitz M, et al (1984): Defining the boundaries of atypical depression. $J$ Clin Psychiatry 45:19-21.

Ravaris CL, Robinson DS, Ives JO, Nies A, Bartlett D (1980): Phenelzine and amitriptyline in the treatment of depression. A comparison of present and past studies. Arch Gen Psychiatry 37:10751080.

Rosenthal NE, Sack DA, Gillin JC, et al (1984): Seasonal affective disorder. A description of the syndrome and preliminary findings with light therapy. Arch Gen Psychiatry 41:72-80.

Stewart JW, Quitkin FM, Terman M, Terman JS (1990): Is seasonal affective disorder a variant of atypical depression? Differential response to light therapy. Psychiatry Res 33:121-128. 